\title{
Artificial livers research output and citations from 2004 to 2017: a bibliometric analysis
}

\author{
Yan Li ${ }^{1}$, Meizhi He ${ }^{1}$, Ziyuan Zou ${ }^{2}$, Xiaohui Bian ${ }^{1}$, Xiaowen Huang ${ }^{2}$, Chen Yang ${ }^{2}$, Shuyi Wei ${ }^{1}$, Shixue \\ Dai Corresp. 3,4 \\ ${ }^{1}$ The Second School of Clinical Medicine, Southern Medical University, Guangzhou, Guangdong, China \\ 2 The First School of Clinical Medicine, Southern Medical University, Guangzhou, Guangdong, China \\ 3 Department of Gastroenterology, Guangdong General Hospital and Guangdong Academy of Medical Sciences, South China University of Technology, \\ Guangzhou, Guangdong, China \\ 4 Guangdong Geriatrics Institute, Guangdong General Hospital and Guangdong Academy of Medical Sciences, South China University of Technology, \\ Guangzhou, Guangdong, China \\ Corresponding Author: Shixue Dai \\ Email address: shixuedai@hotmail.com
}

Background: Researches on artificial livers greatly contribute to the clinical treatments for liver failure. This study aimed to evaluate the research output of artificial livers and citations from 2004 to 2017 through a bibliometric analysis. Methods: A list of included articles on artificial livers were generated after a comprehensive search of the Web of Science (WoS) Core Collection (from 2004 to 2017) with the following basic information: number of publications, citations, publication year, country of origin, authors and authorship, funding source, journals, institutions, keywords, and research area. Results: 968 included articles ranged from 47 citations to 394 citations with a fluctuation. The publications were distributed in 12 countries, led by China $(n=212)$ and the US $(n=207)$. There were strong correlations of the number of citations with authors $\left(r^{2}=0.133, p<\right.$ $0.001)$, and countries $\left(r^{2}=0.275, p<0.001\right)$, while no correlations of the number of citations with the years since publication $\left(r^{2}=0.016, p=0.216\right)$, and funding $\left(r^{2}<0.001, p=\right.$ 0.770 ) were identified. Keyword analysis demonstrated that with the specific chang e of "acute liver failure ", decrease in "bioartificial livers" and "hepatocyte", and increase in "tissue engineering" were identified. The top 53 cited (T53) keyword and keyword plus (including some duplicates counts) were identified, led by bioartificial liver (405 citations) and hepatocyte (248 citations). The top 50 cited (T50) keywords bursts were mainly "Blood" (2004-2008), "hepatocyte like cell" (2008-2015) and "tissue engineering" (2014-2017). All keywords could be classified into four categories: bioartificial livers $(57.40 \%)$, blood purification (25.00\%), clinical (14.81\%), and other artificial organs (2.78\%). Discussion: This study shows the process and tendency of artificial livers research with a comprehensive analysis on artificial livers. However, although it seems that the future of artificial livers shows brighter to hepatocyte transplantation, the systems of artificial livers 
now are inclined to focusing on blood purification, plasma exchange etc. 


\section{Artificial livers research output and citations from 2004 to 2017: a bibliometric}

\section{2 analysis}

4 Yan $\mathrm{Li}^{1 *}$, Meizhi $\mathrm{He}^{1 *}$, Ziyuan $\mathrm{Zou}^{2}$, Xiaohui Bian ${ }^{1}$, Xiaowen Huang ${ }^{2}$, Chen Yang ${ }^{2}$, Shuyi Wei ${ }^{1}$, 5 Shixue Dai ${ }^{3,4}$

$6 \quad$ *These authors contributed equally to this work.

$8{ }^{1}$ The Second School of Clinical Medicine, Southern Medical University, Guangzhou 510515,

9 Guangdong, China.

$10{ }^{2}$ The First School of Clinical Medicine, Southern Medical University, Guangzhou 510515,

11 Guangdong, China

$12{ }^{3}$ Department of Gastroenterology, Guangdong General Hospital and Guangdong Academy of

13 Medical Sciences, South China University of Technology, Guangzhou 510080, Guangdong, China

$14{ }^{4}$ Guangdong Geriatrics Institute, Guangdong General Hospital and Guangdong Academy of

15 Medical Sciences, South China University of Technology, Guangzhou 510080, Guangdong,

16 China. 
19 Shixue Dai, shixuedai@hotmail.com

20 ABSTRACT

21 Background: Researches on artificial livers greatly contribute to the clinical treatments for liver

22 failure. This study aimed to evaluate the research output of artificial livers and citations from 2004

23 to 2017 through a bibliometric analysis.

24 Methods: A list of included articles on artificial livers were generated after a comprehensive

25 search of the Web of Science (WoS) Core Collection (from 2004 to 2017) with the following basic

26 information: number of publications, citations, publication year, country of origin, authors and

27 authorship, funding source, journals, institutions, keywords, and research area.

28 Results: 968 included articles ranged from 47 citations to 394 citations with a fluctuation. The

29 publications were distributed in 12 countries, led by China $(n=212)$ and the US $(n=207)$. There

30 were strong correlations of the number of citations with authors $\left(r^{2}=0.133, p<0.001\right)$, and

31 countries $\left(r^{2}=0.275, p<0.001\right)$, while no correlations of the number of citations with the years

32 since publication $\left(r^{2}=0.016, p=0.216\right)$, and funding $\left(r^{2}<0.001, p=0.770\right)$ were identified.

33 Keyword analysis demonstrated that with the specific change of "acute liver failure", decrease in

34 "bioartificial livers" and "hepatocyte", and increase in "tissue engineering" were identified. The

35 top 53 cited (T53) keyword and keyword plus (including some duplicates counts) were identified,

36 led by bioartificial liver (405 citations) and hepatocyte (248 citations). The top 50 cited (T50)

37 keywords bursts were mainly "Blood" (2004-2008), "hepatocyte like cell” (2008-2015) and "tissue

38 engineering" (2014-2017). All keywords could be classified into four categories: bioartificial 
39 livers $(57.40 \%)$, blood purification $(25.00 \%)$, clinical $(14.81 \%)$, and other artificial organs $40(2.78 \%)$.

41 Discussion: This study shows the process and tendency of artificial livers research with a 42 comprehensive analysis on artificial livers. However, although it seems that the future of artificial

43 livers shows brighter to hepatocyte transplantation, the systems of artificial livers now are inclined 44 to focusing on blood purification, plasma exchange etc.

45 Subjects: Data Science, Gastroenterology and Hepatology, Statistics

\section{INTRODUCTION}

Owing to the high mortality of liver failure, numerous studies had investigated its treatment. Artificial liver was a promising kind of treatment for liver failure. In clinical practice, different kinds of bioartificial systems, blood purification and hepatocyte transplantation had already been applied in liver failure (Naruse $K \&$ Tang $W \&$ Makuuch M, 2007; Wallin J A, 2005). However, a great deal of obstacle and setback were experienced in investigating artificial livers (Carpentier B\& Gautier A \& Legallais C, 2009).

In 1992 and 1994, Ash et al. (Ash et al., 1992; Ash S R, 1994) set a precedent in performing

55 the first liver dialysis which was previously named as Biologic-DT. Subsequently, Stange and

56 Mitzner (Stange et al., 2000) initially developed the Molecular Adsorbent Recirculating System

57 (MARS). Furthermore, various bioartificial liver systems had been reported in nine clinical studies 

since 1990 (Park J K \& Lee D H, 2005). Although artificial liver was considered as one of the most effective treatment for liver failure, the definition of artificial liver still remains obscure.

Additionally, in 2006, K. Onodera et al. (K. Onodera et al., 2006) classified artificial livers into three categories: bioartificial liver, blood purification, and hepatocyte transplantation. In the early works, liver support devices were considered as the treatments of liver failure, and these devices has developed into two different strategies: blood purification and bioartificial liver. The purpose of the former was the removal of toxins in the blood related to coma and cerebral edema, while the latter's intention was to provide metabolic, detoxic, and synthetic function of hepatocytes. However, both of these devices were restricted to the lack of both suitable animal models of liver failure and complete understanding of the pathophysiology of liver failure. Thus, hepatocyte transplantation had developed.

Bibliometric sciences provide a statistical and quantitative analysis of publications and offer a convenient way to visibly measure researchers' efforts in the investigation of a specific field (Ashok et al., 2016; Yao et al., 2018). Though bibliometric methods aim to make comments on qualitative features, the major purpose of its analysis is to transform something intangible (scientific quality) into a manageable entity (Wallin $J$ A, 2005). Citations analysis is a bibliometric process that determine the influence of an article and make further explanations according to the original information about authors and journals (Schmidt et al., 2015). The more cited an article is, the greater influence it makes in a specific area (Eyrewalker $A \& \&$ Stoletzki N, 2013). Despite the inevitable limitations (Wallin $J A, 2005$ ) of bibliometric analysis in assessing research quality, 
78

79

80

81

82

83

84

85

86

87

88

89

90

91

92

93

94

95

96

bibliometric analysis is widely known as one of the best measurements of research trend (Zhou et al., 2018).

This study is the first multicenter retrospective study on artificial livers with bibliometric analysis, based on K. Onodera et al.'s definition of artificial livers. It aimed at evaluating artificial livers output and citations from 2004 to 2017 with a bibliometric analysis, which helps researchers understand the development process of artificial livers and provide guidance for the future direction of further researches.

\section{MATERIALS \& METHODS}

\section{Search strategy}

With strict inclusion criteria, WoS provides adequate researches for literature analysis, including keywords, authors, institutions, countries, and publication years, which were vital for bibliometric analysis. Therefore, we conducted a citation search of the Web of Science Core Collection from 2004 to 2017. The keywords and free words were 'Bioartificial Liver' or 'Bioartificial Livers' or 'Liver, Bioartificial' or 'Livers, Bioartificial' or 'Artificial Liver' or 'Artificial Livers' or 'Livers, Artificial' on topic field. All retrieval was conducted on 25th May 2018 to avoid possible changes in citation rate. After all data were extracted, articles were ranked by citation number. 
97 Two independent investigators (M.Z. He and X.H. Bian) respectively screened all the titles and

98 abstracts to select eligible articles according to the inclusion criteria. (Fig. 1). Any questions were

99 resolved by discussion and the help of the third independent investigator (Y. Li $)$. Data were

100 retrieved from literature if meeting the following criteria: (1) The main content should be related

101 to the study, (2) Literature could be any type of researches (such as article, review, editorial

102 material and meeting abstract), (3) Literature involving other topics related to the study. The

103 exclusion criteria were: (1) Duplicates, (2) The titles and abstract of papers were not related to the

104 study, (3) The abstract of paper was not accessible.

105

106 Evaluation of included articles

107 The following data were extracted from the 968 included articles by one investigator (M.Z. He) as

108 followed:(1) the number of publications, (2) citations, (3) publication year, (4) country of origin,

109 (5) authors and authorship, (6) funding source, (7) journals, (8) institutions, (9) keywords and

110 research fields. Articles that were collaborative work of authors from multiple countries were also

111 identified. In addition, T18 journals of T100 articles were evaluated with IFs which were in

112 accordance with the 2017 edition of Journal Citation Reports (JCR): Science Edition (2017-2018). 
115 With GraphPad Prism version 6.0, the Spearman test was used to evaluate the strength and

116 direction of the linear relationship between the number of T100 citations and the number of

117 authors, year since publication, funding, and countries in each publication. Furthermore, the

118 Spearman test with GraphPad Prism was also applied to evaluate the correlation of citation index

119 between different databases (Web of Science Core Collection and Scopus) and the correlations of

120 the number of impact factor with the number of T100 articles per journals and the number of

121 average citations The citation index was measured as the true impact of an article independent of

122 short-lived trends (Yuanhui Liu et al., 2016) and the impact factor usually serves as indicator for

123 reflecting the average number of yearly citations for recent papers published in the journal

124 (Garfield E, 2006). Both of them were used to assess the equality of research output in most

125 bibliometric analyses. All probability values were two-tailed, meanwhile, the threshold of the

126 number of T100 citations, countries, and authors for significance was set at $p<0.001$, while others

127 were not.

128

129 Bibliometric analysis

130 Using the Online Analysis platform of Literature Metrology (http://bibliometric.com/), the trend

131 of the number of publications, the trend of country of origin, the cooperation between countries,

132 and the trend of keywords were shown. All the data were standardized by the frequency of 133 occurrence. 
134 With CiteSpace, the network map of authors, co-authors and institutions were shown by 135 publication year and the number of citations via citation-tree rings, while the network map of 136 keywords and keyword plus were shown only according to number of citations (Chen C,2004).

\section{RESULTS}

\section{Total number of published items}

140 The number of published items on artificial livers was considered as an index of research 141 productivity. A total of 2,954 papers were identified after the initial record in the WoS from 1986 142 to 2017. From 2,954 records, 1622 titles were excluded, because 1,532 titles were unrelated to 143 artificial livers, 90 titles were not mainly discussing artificial livers, and four titles were duplicates.

144 In addition, 364 articles were excluded, because 231 abstracts of which were not accessible, 89 145 abstracts were not mainly discussing artificial livers and 44 abstracts were unrelated to artificial 146 livers. Thus, 968 articles were extracted in WoS during the period from 2004 to 2017. The number 147 of articles reached a peak of 95 in 2005 and rapidly decreased to a nadir of 63 in 2007 , then 148 fluctuated up and down during 2008 to 2015 (Fig. 2 A). However, it reached the lowest point in 1492016 and grew up again in 2017. 
152 A total of 12 different countries contributed to the literature on artificial livers (Fig. 2 B). China

153 and the US produced similar number of articles during 2004 to 2017, while a decrease in the

154 number of articles was identified for Japan. Among the international cooperation (Fig. 3), and the

155 collaboration between the US and China was the most frequent, followed by US-Germany.

156

157 Citation count and possible factors influencing citations

158 Among the 968 included articles, T100 publications on artificial livers were identified by WoS

159 and ranked by the number of citations (Table 1; Table S1). The median number of citations was

160198 (ranged from 47 to 394), with 20 papers cited over 100 times. The median number of citation

161 index was 36.31 (ranged from 3.61 to 69 ), and there was strong correlation between citation index

162 and the number of the citations $\left(r^{2}=0.343, p<0.001\right.$; Fig. S1 A) per article in WoS. In addition, the

number of citations and citation index of every article in Scopus database were strongly correlated,

and the number of citation index between WoS and Scopus was also strongly correlated $\left(r^{2}=0.350\right.$,

$p<0.001 ; r^{2}=0.990, p<0.001$, respectively; Fig. S1 B, S1 C). Both the mean values and the

standard deviations (SDs) of the number of citations and citation index for WoS and Scopus

Database were evaluated. The mean values of the number of citations for these two databases were

$79.270(\mathrm{SD}=45.425$,$) and 83.000(\mathrm{SD}=49.560)$, respectively, while the mean values of citation

index were independently $0.040(\mathrm{SD}=0.023)$ and $0.041(\mathrm{SD}=0.025)$. The oldest cited paper was

170 written by Chan, C et al. (Chan et al., 2004) and was published in 2004. The latest paper written

171 by Larsen, FS et al. (Larsen et al., 2016) was published in 2016. 
possible correlations between the number of citations and years since publication, authors, funding,

174

175

176

177

178

179

180

181

182

183

184

185

186

187

188

189

190

and countries (Fig. 4). There were strong correlations of the number of citations with authors $\left(r^{2}=0.133, p<0.001\right)$ and countries $\left(r^{2}=0.275, p<0.001\right)$. While no correlations of the number of the citations with years since publication $\left(r^{2}=0.016, p=0.216\right)$, and funding $\left(r^{2}<0.001, p=0.770\right)$ were identified.

\section{Journals}

More than 60 journals contributed to T100 publications, and T18 journals of T100 publications are listed in table 2. Articles were most frequently published in Biomaterials $(n=9)$, followed by Tissue Engineering $(n=7)$, Liver Transplantation $(n=6)$, and Biotechnology and Bioengineering $(n=6)$. T18 journal IFs of T100 articles ranged from 1.59 to 17.016 with the median number of IFs

(9.303. Many of the T100 articles were published in high-IF journals, however, these IFs were poorly correlated with the number of T100 articles $\left(r^{2}=0.023, p=0.556\right.$; Fig. S2 A), and the number of average citations $\left(r^{2}=0,060, p=0.345\right.$; Fig. S2 B $)$.

\section{Authorship and institutions}

More than 3500 authors contributed to the included articles and the majority (89\%) of T100 articles were produced by cooperation work involving $\geq 3$ authors. The top five cited authors ranked by the 
191 number of articles were listed in Table 3. The most frequently appearing authors was Chamuleau,

192 RAFM, who authored 32 included articles (2 as first and 5 as corresponding author) with total 387

193 citations, followed by Li, LJ, who authored 31 included articles ( 3 as first and 28 as corresponding

194 author) with a total of 127 citations.

195 CiteSpace detected the information on author and co-cited authors and presented them 196 through a network map (Fig. 5 A, B). Among the cooperation between authors, Li, LJ ranked the 197 first (cooperated with 30 authors), followed by Chamuleau, RAFM (cooperated with 28 authors). 198 According to the network map of co-cited authors, Demetriou AA (210 citations) ranked first, 199 followed by Nyberg SL (154 citations), and Van de K (153 citations).

Among the top five institutions of included articles (Table 4), the leading institutions with the 201 most productive articles was University Amsterdam ( $\mathrm{n}=85$, with 1066 citations), followed by Zhejiang University ( $\mathrm{n}=53$, with 160 citations). In addition, University Pittsburgh, National University Singapore, and Harvard University possessed 49, 44, and 40 included articles, 204 respectively (with 211,211 , and 225 citations, respectively).

206 (Fig. 5 C). Among the network map, Zhejiang University ranked the first with the cited numbers 207 of 45, followed by Harvard University (with 33 citations), Kyushu University (with 33 citations) 208 and University of Amsterdam (with 28 citations). 
211 Keywords with bibliometric analysis provided information about directions and trend of research.

212 A rough estimate of research changes could be found with figure 6 . The keywords of 'bioartificial

213 liver' and 'hepatocyte' appeared less and less during 2004 to 2017, however, 'tissue engineering'

214 was appeared more frequently after 2011, and almost became the most frequently used keywords

215 during the period from 2015 to 2017. In addition, it was not difficult to find that each time the

216 keyword of 'acute liver failure' increase, either 'bioartificial livers' or 'tissue engineering' follows

217 the rise.

T53 keyword and keyword plus (including some duplicates counts) ranked by the count (the total citations of the publications in which the keyword and keyword plus appeared) were identified and analyzed with CiteSpace (Fig. 5 D; Fig. S1), among which bioartificial liver ranked the first $(n=405)$, followed by hepatocyte $(n=248)$, in vitro $(n=172)$ and transplantation $(n=151)$. (Additional files 5), clearly indicating the research frontiers over time. The time interval was a blue line and the time period that represents a burst keyword category was a red line, suggesting the beginning and the end of the time interval of each burst (Bornmann L \& Mutz R, 2015). The keywords with the strongest citation bursts were firstly ignited by "blood" from 2004 to 2007,

227 followed by "blood purification" (2006-2010) and "hepatocyte like cell" (2008-2015). Keywords

228 with the strongest citation bursts after 2010 were listed as follows: "prometheus" (2012-2013),

229 “plasma exchange" (2014-2017) and "tissue engineering” (2014-2017). 
230 More than 3900 keywords were extracted from the 968 publications. After the data were

231 combined with consent word, 1,732 keywords were ranked by the number of occurrences. Among

232 them, 108 keywords appearing at least seven times, were identified and analyzed with Table

233 5These keywords showed the main content of studies on artificial livers and research trend of this

234 field. These keywords were classified into four domains based on two independent investigators

235 (Meizhi He, Yan Li): bioartificial livers, blood purification, clinical, and other artificial organs.

236 Among the 108 keywords, the bioartificial livers domain ranked the first with the highest

237 percentage $(57.40 \%)$. The blood purification domain was followed with $25.00 \%$, the clinical was

$23814.81 \%$, and other artificial organs was $2.78 \%$.

239

The Human liver technology topic of human liver domain showed the highest percentage

240

(15.74\%), followed by human liver tissues and organs (14.81\%). Among them, the most frequency

241

of keyword was 'Amanitaphalloides' $(n=95)$ in hepatocyte related substance topic, followed by

242 'academic medical center bioartificial liver' $(n=83)$ in human liver technology topic, 'airlift reactor' $(n=78)$ in Bioreactor topic, 'bilirubin' $(n=68)$, 'alginate beads' $(n=62)$ and 'antioxidant' $(n=59)$ in Hepatocyte related substance topic, 'artificial liver' $(n=58)$ in human liver technology topic. Additionally, “extracorporeal” $(n=30)$, 'hepatocyte' $(n=39)$, 'a hepatic time' $(n=36)$, 'albumin synthesis' $(n=31)$, 'galactoses' $(n=37)$ and '3D cell culture' $(n=55)$ appeared thirty or 247 more than thirty times. 


\section{DISCUSSION}

\section{Total number of published items}

254 This study is the first bibliometric analysis on artificial livers. The results of the number of articles each year had demonstrated that the research on artificial livers fluctuated from 2005 to 2014 .

257 the average annual incidence rate of liver failure decreased ()(2) some investigators had finished their projects on artificial livers and changed their research orientation (Kayoko Sugawara \& 


\section{Country of origin and institutions}

270 In growth trends of countries, the result showed that China played an important part in the research

271 on artificial livers. This was probably due to the largest population of domestic hepatitis B patients

272 (Kjaergard et al., 2003) and an undesirable liver transplantation situation in China (Nielsen F E,

273 1998). The high incidence rate of hepatitis B in China largely led to this increasing number of

274 investigations of interest (Chen $X \&$ Shen $Y \&$ Xiang $W$, 2006). US, Japan and Germany

275 collectively contributed to a predominant number of publications, verifying that countries with

276 higher economic ranking were associated with larger quantity and better quality of biomedical

277 publications (Qiu et al., 2010). In addition, USA, Japan and Germany were developed countries

278 and had huge disease burden of liver failure, promoting more research interest and more research

279 funding as well in artificial livers researches (Gillum LA et al., 2011). Figure 2 B indicated that

280 artificial livers researches in the US were influential worldwide. And the results of country of

281 origin also lead to the results of institution. This finding confirmed that the great demand in

282 effective treatment strategies could encourage the development of scientific researches in this field.

\section{Citation count and possible factors influencing citations}

Among the 968 included publications, we extracted T100 publications and made a list in a table 
28720 publications cited over 100 times. This number was quite small, for the reason that citations

288 differed between different professional domains, mainly contributing to the number of researchers

289 in specific medical fields (Tang et al., 2016). In McDowell et al.' s (Mcdowell et al., 2017) research

290 on pediatric liver transplantation, the citations of T10 publications ranged from 175 to 635 ,

291 significantly fewer than those of hypertension (2,242-7,248) (Oh Y S \& Galis Z S, 2014) and

292 diabetes (3,420-10,292) (Zhao et al., 2016). In order to minimize the effect of publication time on

293 citations, the citation index was applied to estimate publications impact on their field in a short

294 period. The results showed that there is high correlation between citations and citation index,

indicating that citations were hardly affected by citation period. Additionally, high correlations

between WoS and Scopus on citations were found with the premise that the citation index was

297

strongly related to citations in Scopus. Besides, through investigating four possible factors that

influence citations, the result demonstrated that the more authors and more countries work

together, the higher quality of an articles could be. However, this phenomenon contradicted

Ahmed et al.'s (Ahmed et al., 2016) research, which concluded that two-authored article was the

most suitable. It seemed that the effect of the number of authors differs between specific research

fields. No correlation between the number of citations and the number of years since publication

was identified, which might be related to the tendency of citing particular papers in researchers

(Azer $S A \&$ Azer $S, 2016$ ). There was also no correlation found between the number of citations 


\section{Journals}

309 Numerous studies had shown that the impact factor of journal was the best indicator for citations

310 (Saha $S \&$ Saint $S \&$ Christakis D A, 2003). However, citations were not clearly affected by IFs of

311 the journals in this analysis (Hecht $F \&$ Hecht $B K \& \operatorname{Sandberg} A$ A, 1998). They found that the

312 majority of the considered as "highest-impact journals" did not report fresh research results. The

313 most trouble was that IF was a quantitative measure of a quality that cannot be quantified.

\section{Authorship}

Analysis of authorship describes the cooperation between authors and the high productive authors, of which the top five cited authors listed, produced more than 400 publications. Thus, they were called "productive authors" (Zongyi Y \& Dongying C \& Baifeng L, 2016). Unfortunately, a small number of prolific authors appeared in the network map of co-cited authors, suggesting that not only the number of publications but also the quality of publications should be assessed in the artificial livers research. 
326 Keyword analysis consists of three parts: (1) a rough estimation of the trend of research directions

327 (2) analysis of the research hotspots and frontiers (3) detailed classification and analysis of research area. The increase of "bioartificial livers" and "tissue engineering" usually followed by the increase of "acute liver failure", because acute liver failure usually developed into serious liver failure, and artificial livers were considered to be the most effective treatment. The keyword of "bioartificial livers" with more than 400 citations decreased during the period from 2004 to 2017. It reached a peak (54 articles) at 2005, and most of them focused on the topic of hollow fiber ( $\mathrm{Abu-}$ Absi et al., 2005; Lu et al., 2005; Nguyen D T \& Brotherton J D \& Chau P C, 2005), bioartificial cell (Aoki et al., 2005; Cheng et al., 2005; Gerlach J C, 2005; Monga et al., 2005), and transplantation (Garkavenko et al., 2005; Liu Z C \& Chang T M, 2005). This finding suggested that many researchers showed great interest in bioartificial livers in 2005 . They made every effort to culture human hepatocytes, rat hepatocytes, and stems cells to support liver functions and improve the device of bioreactors (Park et al., 2005). The keyword "bioartificial livers" covered the meaning of "hepatocyte", and thus the trend of "hepatocyte" was similar with "bioartificial livers". Tissue engineering studies on 3D technology (Arai et al., 2017), mathematical model (Chapman et al., 2017), Liver microencapsulation technique (Chapman et al., 2017) and stems cells (Kadota et al., 2014) were mainly carried out in 2016 and 2017. According to T50 keywords of artificial livers, we extracted top three research hotspots and listed them as follows:

i. Bioartificial liver: A bioartificial liver system incorporated hepatocytes into a mechanical, 345 albumin dialysis-based artificial liver support device to replace liver function (Nicolas et al., 
346 2017). The two main elements of bioartificial livers were bioreactors and cell material. There was

347 no definition of which kind of cell is the most ideal, and many researchers were still in search of

348 the most ideal cells.

349 ii. Hepatocyte: Hepatocyte was known as the function unit of liver. It was ideal to investigate a

350 kind of hepatocyte with regeneration ability and necessary functions for substitution of necrotic or

351 dysfunctional hepatocytes.

352 iii. Transplantation: With the development of liver regenerative medicine, cell transplantation was

353 becoming an increasingly popular topic, and many researchers showed great interest in it.

354 The keywords bursts were considered as research frontiers over time. We extracted some

355 keyword burst and divided them into three parts as follows:

356 i. Blood and blood purification: Acute liver failure would be found variety of toxic substances in

357 blood. Therefore, researches on artificial livers mainly focus on extracorporeal blood purification

358 (hemodialysis, hemofiltration, hemodiafiltration, plasmapheresis, hemodsorption, cell-based

359 therapy, etc.) (Thongboonkerd V, 2010; Nie et al., 2015).

360 ii. Plasma exchange and Prometheus: Since relatively simple detoxification devices use in 1999

361 (albumin dialysis, AD, MRAS) and 2003 (fractionated plasma separation, FPS, Prometheus), the

362 treatment of liver failure had improved a lot (Davenport et al., 2015). However, prospective trials

363 of extracorporeal support with albumin dialysis, superflux dialyzers in series with absorption

364 columns, and bioartificial devices containing hepatocytes have not demonstrated a significant 
365 survival advantage. Therefore, researchers found that before liver failure, plasma exchange

366 improved cardiovascular stability, extending survival and increase overall survival.

367 iii. Tissue engineering: "Tissue engineering" appeared in 2014 for the first time and continued

368 until 2017. It's the best prediction that liver function could be restored with the technology of

369 tissue engineering, and even now, many researches were working hard to continuously exceling

370 themselves in perfecting the technology of tissue engineering. The future was bright for patients

371 with serious liver failure in receiving a "new" liver through tissue engineering.

372 Among the four domains mentioned, the domain of "bioartificial livers" occupied the largest

373 portion and the other artificial organs domain occupied the smallest portion. This suggested that

374 bioartificial liver would still be a treatment strategy of great potential in liver failure and needed

375 more researchers to promote its development. At the same time, the occupation of clinical domain

376 suggested that clinical requirement was one of the strongest motivations for stimulating the

377 development of artificial livers. And the result of research fields was similar to the four domains

378 of keywords.

379 There were some limitations in this study. Firstly, the data were only extracted from WoS

380 database. Secondly, it was difficult to make definite predictions on the development trend as well

381 as the most popular topic of interest since researches on artificial liver was still developing slowly

382 though with great potential. Although limitations as listed before, this study had provided the

383 tendency and main context of researches in artificial livers, indicating that hepatocyte 
384 transplantation might be frontiers in artificial livers but now the liver support system could gain

385 better clinical effect.

386

387 CONCLUSIONS

388 The number of publications on artificial livers fluctuated from 2004 to 2017, most of which are

389 Chinese publications. After excluding several confounding factors (database, number of authors, 390 countries, years since publication and funding), the citations roughly estimated the quality of the 391 included articles. The analysis of authorship and institutions also contributed to evaluating the 392 quality of the included articles. In addition, through a detailed analysis which roughly assessed the 393 research tendency, hotspots and frontiers of keywords, this study showed the progress and research 394 trend of artificial livers. However, although it seems that the future of artificial livers shows 395 brighter to hepatocyte transplantation, the systems of artificial livers now are more focusing on 396 blood purification, plasma exchange etc.

397

398 FIGURE LEGENDS

Figure 1 Overview of article selection process.

400

Figure 2 Numbers of included articles (A) and the growth trends of countries (B) from 2004

401

to 2017 . 
402 Figure 3 Interactions between countries of the included articles.

403 Figure 4 Correlations between the number of citations and the number of funding (A), years

404 since publication (B), countries (C) and authors (D).

405 Figure 5 Network map of authors (A), co-cited authors (B), institutions (C) and keywords

406 (D).

407 Figure 6 Growth trends of keywords on artificial livers from 2004 to 2017.

408

409

ABBREVIATIONS

410 WoS Web of Science

411 T18 The top 18 cited

412 IFs Impact Factors

413 T100 The top 100 cited

414 T5 The top 5 cited

415 T53 The top 53 cited

416 T50 The top 50 cited

417 JCR Journal Citation Reports

418 MARS Molecular Adsorbent Recirculating System 
419 AD albumin dialysis

420 FPS fractionated plasma separation

421 SD standard deviation

422

423 ACKNOWLEDGEMENTS

424 The authors would like to thank editors and the anonymous reviewers for their valuable comments

425 and suggestions to improve the quality of the paper.

426

427 Data Availability

428 The following information was supplied regarding data availability:

429 Raw data is provided in the supplemental files.

430

431 REFERENCES

432 Naruse K, Tang W, Makuuch M. 2007. Artificial and bioartificial liver support: a review of 433 perfusion treatment for hepatic failure patients. World J Gastroenterol, 13:1516-1521. DOI:

434 10.3748/wjg.v13.i10.1516. 
435

436

437

438

439

440

441

442

443

444

445

446

447

448

449

450

451

452

453

Wallin J A. 2005. Bibliometric methods: pitfalls and possibilities. Basic Clin Pharmacol Toxicol, 97:261-275. DOI: 10.1111/j.1742-7843.2005.pto_139.x.

Carpentier B, Gautier A, Legallais C. 2009. Artificial and bioartificial liver devices: present and future. Gut, 58:1690-1702. DOI: 10.1136/gut.2008.175380.

Ash S R, Blake D E, Carr D J, Howard T, Makowka L. 1992. Clinical effects of a sorbent suspension dialysis system in treatment of hepatic coma (the BioLogic-DT). Int J Artif Organs, 15:151-161.

Ash S R. 1994. Hemodiabsorption in Treatment of Acute Hepatic Failure and Chronic Cirrhosis with Ascites. Artif Organs, 8:355-62.3 DOI: 10.1111/j.1525-1594.1994.tb02216.x.

Stange J, Mitzner S R, Klammt S, Freytag J, Peszynski P, Loock J, Hickstein H, Korten G, Schmidt R, Hentschel J, Schulz M, Löhr M, Liebe S, Schareck W, Hopt UT. 2000. Liver support by extracorporeal blood purification: A clinical observation. Liver Transpl, 6:603-613. DOI: $10.1053 /$ jlts.2000.7576.

Park J K, Lee D H. 2005. Bioartificial liver systems: current status and future perspective. $J$ Biosci Bioeng, 99:311-319. DOI: 10.1263/jbb.99.311.

Onodera K, Sakata H, Yonekawa M, Kawamura A. 2006. Artificial liver support at present and in the future. J Artif Organs, 9:17-28. DOI: 10.1007/s10047-005-0320-1.

Ashok A, Damayanthi D, Sindhuja T, Sandro C Esteves, Avi Harlev, Ralf Henkel, Shubhadeep Roychoudhury, Sheryl Homa, Nicolás Garrido Puchalt, Ranjith Ramasamy, 
454 Ahmad Majzoub, Kim Dao Ly, Eva Tvrda, Mourad Assidi, Kavindra Kesari, Reecha 455 Sharma, Saleem Banihani, Edmund Ko, Muhammad Abu-EImagd, Jaime Gosalvez, Asher 456 Bashiri. 2016. Bibliometrics: tracking research impact by selecting the appropriate metrics. Asian 457 J Androl, 8:296-309. DOI: 10.4103/1008-682X.171582.

458

459

460

461

462

463

464

465

466

467

468

469

470

Yao H Q, Wan J Y, Wang C Z, Li L, Wang J, Li Y, Huang WH, Zeng J, Wang Q1, Yuan CS

. 2018. Bibliometric analysis of research on the role of intestinal microbiota in obesity. Peer $J$, 6:

DOI: $10.7717 /$ peerj.5091.

Wallin J A. 2005. Bibliometric methods: pitfalls and possibilities. Basic Clin Pharmacol Toxicol, 97:261-275. DOI: 10.1111/j.1742-7843.2005.pto_139.x.

Schmidt S, Bundschuh M, Scutaru C,Klingelhoefer D, Groneberg DA, Gerber A. 2015. Hepatitis B: global scientific development from a critical point of view. J Viral Hepat, 21:786793. DOI: $10.1111 /$ jvh.1220 5.

Eyrewalker A, Stoletzki N. 2013. The Assessment of Science: The Relative Merits of PostPublication Review, the Impact Factor, and the Number of Citations. PLoS Biol, 11: e1001675. DOI: 10.1371/journal.pbio.1001675.

Zhou H Q, Tan W L, Qiu Z T, Yiyan Song, Shaowei Gao. 2018. A bibliometric analysis in gene research of myocardial infarction from 2001 to 2015. Peer J, 6: DOI: 10.7717/peerj.4354. 
471 Liu Y-H, Wang S-Q, Xue J-H, Liu Y, Chen J-Y, Li G-F, He P-C, Tan N. 2016. Hundred top-

472 cited articles focusing on acute kidney injury: a bibliometric analysis. BMJ OPEN, 6:7 DOI:

473 10.1136/bmjopen-2016-011630.

474

475

476

477

478

479

480

481

482

483

484

485

486

487

488

Garfield E. 2006. The history and meaning of the journal impact factor. Journal of the American Medical Association, 295:90-93 DOI:10.1001/jama.295.1.90.

Chen C. 2004. Searching for intellectual turning points: progressive knowledge domain visualization. Proc Natl Acad Sci U S A, 101:5303-5310 DOI: 10.1073/pnas.0307513100

Chan C, Berthiaume F, Nath B D, Tilles AW, Toner M, Yarmush ML. 2004. Hepatic tissue engineering for adjunct and temporary liver support: critical technologies. Liver Transpl, 10:13311342. DOI: $10.1002 / 1 \mathrm{t} .20229$.

Larsen F S, Schmidt L E, Bernsmeier C, Rasmussen A, Isoniemi H, Patel VC, Triantafyllou E, Bernal W, Auzinger G, Shawcross D, Eefsen M, Bjerring PN, Clemmesen JO, Hockerstedt K, Frederiksen HJ, Hansen BA, Antoniades CG, Wendon J. 2016. High-volume plasma exchange in patients with acute liver failure: An open randomized controlled trial. J Hepatol, 64:69-78. DOI: 10.1016/j.jhep.2015.08.018.

Bornmann L, Mutz R. 2015. Growth rates of modern science: A bibliometric analysis based on the number of publications and cited references. J Assoc Inf Sci Technol, 66:2215-2222. DOI: 10.1002/asi.23329. 
489

490

491

492

493

494

495

496

497

498

499

500

501

502

503

504

505

506

Phillippe Ichai, Samuel D. 2011. Epidemiology of liver failure. Clinics \& Research in

Hepatology \& Gastroenterolog, 35:610-617. DOI: 10.1016/j.clinre.2011.03.010.

Sugawara K, Nakayama N, Mochida S. 2012. Acute liver failure in Japan: definition, classification, and prediction of the outcome. Journal of Gastroenterology, 47:849-861. DOI: $10.1007 / \mathrm{s} 00535-012-0624-\mathrm{x}$

Todo S, Furukawa H. 2011. Living donor liver transplantation for adult patients with hepatocellular carcinoma: experience in Japan. Journal of Hepatobiliary Surgery, 240:451. DOI:

\subsection{7/01.sla.0000137129.98894.42Tanaka M, Katayama F, Kato H, Hideo Tanaka,} Jianbing Wang, You Lin Qiao, Manami Inoue. 2011. Hepatitis B and C Virus Infection and Hepatocellular Carcinoma in China: A Review of Epidemiology and Control Measures. $J$ Epidemiol, 21:401-416. DOI: 10.2188/jea.JE20100190.

Ogura Y, Hori T, El Moghazy W M, Yoshizawa A, Oike F, Mori A, Kaido T, Takada Y, Uemoto S. 2010. Portal pressure $<15 \mathrm{~mm} \mathrm{Hg}$ is a key for successful adult living donor liver transplantation utilizing smaller grafts than before. Liver Transpl, 16:718-728. DOI: $10.1002 / 1 \mathrm{t} .22059$.

Kjaergard L L, Liu J, Alsnielsen B, Gluud C. 2003. Artificial and Bioartificial Support Systems for Acute and Acute-on-Chronic Liver Failure: A Systematic Review. JAMA, 289:217-222. DOI: 10.1001/jama.289.2.217. 
507 Nielsen F E. 1998. Publication outcome of research funding by the Danish Heart Foundation 1988-

508 1990. Ugeskr Laeg, 160:4644-4648.

509 Chen X, Shen Y, Xiang W. 2011. Distribution Characteristics of Hepatitis B Serological Markers 510 in Hospitalized Children and Adolescents in Zhejiang, China between 2006 and 2010. Gut Liver, 511 5:210. DOI: 10.5009/gnl.2011.5.2.210.

512 Qiu L, Binns C W, Zhao Y, Zhang K, Xie X. 2010. Hepatitis B and breastfeeding in Hangzhou, 513 Zhejiang Province, People's Republic of China. Breastfeed Med, 5:109-112. DOI: 514 10.1089/bfm.2009.0093.

515 Leslie A. Gillum, Christopher Gouveia, E. Ray Dorsey, Mark Pletcher, Colin D. Mathers,

516 Charles E. McCulloch, S. Claiborne Johnston. 2011. NIH Disease Funding Levels and Burden 517 of Disease. Plos One, 6: e16837. DOI: 10.1371/journal.pone.0016837.Tang X, Gong W, Yuan

518 F, Ran Li, Xiaomei Han, Silin Huang, Fachao Zhi, Bo Jiang. 2016. Top-cited articles in 519 digestive system disease from 1950 to 2013. J Gastroenterol Hepatol, 31:107-11 DOI: $520 \quad$ 10.111/jgh.13032.

521 Mcdowell D T, Darani A, Shun A, Thomas G, Holland AJA2017. A bibliometric analysis of 522 pediatric liver transplantation publications. Pediatr Transplant, 21: e12913. DOI: 523 10.111/petr.12913. 
524 Oh Y S, Galis Z S. 2014. Anatomy of success: the top 100 cited scientific reports focused on

525 hypertension $\quad$ research. $\quad$ Hypertension, $\quad 641-647 . \quad$ DOI:

526 10.1161/HYPERTENSIONAHA.113.02677.

527 Zhao X, Guo L, Lin Y, Wang H, Gu C, Zhao L, Tong X. 2016. The top 100 most cited scientific

528 reports focused on diabetes research. Acta Diabetologica, 53:1-14. DOI: 10.1007/s00592-015$529 \quad 0813-1$.

530 Ahmed A, Adam M, Ghafar N A,Murtala MUHAMMAD, Nader Ale EBRAHIM . 2016.

531 Impact of Article Page Count and Number of Authors on Citations in Disability Related Fields: A

532 Systematic Review Article. Iran J Public Health, 45:1118-1125.

533 Azer S A, Azer S. 2016. Bibliometric analysis of the top-cited gastroenterology and hepatology

534 articles. Bmj Open, 6: e009889. DOI: 10.1136/bmjopen-2015-009889.

535 Jean-Michel F, Currie D J. 2013. Big Science vs. Little Science: How Scientific Impact Scales 536 with Funding. Plos One, 8: e65263. DOI: 10.1371/journal.pone.0065263.

537 Saha S, Saint S, Christakis D A. 2003. Impact factor: a valid measure of journal quality? J Med 538 Libr Assoc, 91:42.

539 Hecht F, Hecht B K, Sandberg A A. 1998. The journal "impact factor": a misnamed, misleading, 540 misused measure. Cancer Genet Cytogenet, 104:77-81. DOI: 10.1016/S0165-4608(97)00459-7. 
541 Zongyi Y, Dongying C, Baifeng L. 2016. Correction: Global Regulatory T-Cell Research from

5422000 to 2015: A Bibliometric Analysis. Plos One, 11: e0162099. DOI:

543 10.1371/journal.pone.0170850.

544 Abu-Absi S F, Seth G, Narayanan R A, Groehler K, Lai P, Anderson ML, Sielaff T, Hu WS.

545 2005. Characterization of a hollow fiber bioartificial liver device. Artif Organs, 29:419-422. DOI:

546 10.1111/j.1525-1594.2005.29070.x.

547 Lu H F, Lim WSZhang P C, Chia S M, Yu H, Mao HQ, Leong KW 2005. Galactosylated poly

548 (vinylidene difluoride) hollow fiber bioreactor for hepatocyte culture. Tissue Eng, 11:1667-1677.

549 DOI: 10.1089/ten.2005.11.1667.

550 Nguyen D T, Brotherton J D, Chau P C. 2005. Enhancing cell viability with pulsating flow in a 551 hollow fiber bioartificial liver. Biotechnol Lett, 27:1511. DOI: 10.1007/s10529-005-1467-9.

552 Aoki T, Koizumi T, Kobayashi Y, Yasuda D, Izumida Y, Jin Z, Nishino N, Shimizu Y, Kato

553 H, Murai N, Niiya T, Enami Y, Mitamura K, Yamamoto T, Kusano M. 2005. A novel

554 method of cryopreservation of rat and human hepatocytes by using encapsulation technique and

555 possible use for cell transplantation. Cell Transplant, 14:609-620. DOI: $556 \quad 10.3727 / 000000005783982710$.

557 Cheng Y B, Wang Y J, Zhang S C, Liu J, Chen Z, Li JJ . 2005. Response of porcine hepatocytes

558 in primary culture to plasma from severe viral hepatitis patients. World J Gastroenterol, 11:7585559 7590. DOI: 10.3748/wjg.v11.i48.7585. 
560 Gerlach J C. 2005. Prospects of the use of hepatic cells for extracorporeal liver support. Acta 561 gastro-enterologica Belgica, 68:358.

562

563

564

565

566

567

568

569

570

571

572

573

574

575

576

577

578

Monga S P S, Hout M S, Baun M J, Amanda Micsenyi, Peggy Muller, Lekha Tummalapalli, Aarati R. Ranade, Jian-Hua Luo, Stephen C. Strom, Jörg C. Gerlach 2005. Mouse fetal liver cells in artificial capillary beds in three-dimensional four-compartment bioreactors. Am J Pathol, 167: 1279. DOI: 10.1016/S0002-9440(10)61215-1.

Garkavenko O, Emerich D F, Muzina M, Muzina Z, Vasconcellos AV, Ferguson AB, Cooper

IJ, Elliott RB. 2005. Xenotransplantation of neonatal porcine liver cells. Transplant Proc, 37:477. DOI: 10.1016/j.transproceed.2004.12.183.

Liu Z C, Chang T M. 2005. Transplantation of bioencapsulated bone marrow stem cells improves hepatic regeneration and survival of $90 \%$ hepatectomized rats: a preliminary repo. Artif Cells Blood Substit Immobil Biotechnol, 33:405-410. DOI: 10.1080/10731190500289834.

Park J, Berthiaume F, Toner M, Yarmush ML, Tilles AW. 2005. Microfabricated grooved substrates as platforms for bioartificial liver reactors. Biotechnol Bioeng, 90:632-44. DOI: 10.1002/bit.20463.

Arai K, Yoshida T, Okabe M, Goto M, Mir TA, Soko C, Tsukamoto Y, Akaike T, Nikaido T, Zhou K, Nakamura M. 2017. Fabrication of 3D-culture platform with sandwich architecture for preserving liver-specific functions of hepatocytes using 3D bioprinter. J Biomed Mater Res, Part A, 105:1583-1592. DOI: 10.1002/jbm.a.35905. 
579 Chapman L A C, Whiteley J P, Byrne H M,Waters SL, Shipley RJ. 2017. Mathematical

580 modelling of cell layer growth in a hollow fibre bioreactor. $J$ Theor Biol, 418:36-56. DOI:

581 10.1016/j.jtbi.2017.01.016.

582

583

584

585

586

587

588

589

590

591

592

593

594

595

Pandolfi V, Pereira U, Dufresne M, Legallais C 2017. Alginate-Based Cell Microencapsulation for Tissue Engineering and Regenerative Medicine. Curr Pharm Des, 23:3833-3844.

Kadota Y, Yagi H, Inomata K, Matsubara K, Hibi T, Abe Y, Kitago M, Shinoda M, Obara

H, Itano O, Kitagawa Y. 2014. Mesenchymal stem cells support hepatocyte function in engineered liver grafts. Organogenesis, 10:268. DOI: 10.4161/org.27879.

Nicolas C T, Hickey R D, Chen H S,Mao SA, Lopera Higuita M, Wang Y, Nyberg SL.

2017. Liver Regenerative Medicine: From Hepatocyte Transplantation to Bioartificial Livers and Bioengineered Grafts. Stem Cells, 35:42. DOI: 10.1002/stem.2500.

Thongboonkerd V. 2010. Proteomics in extracorporeal blood purification and peritoneal dialysis.

J Proteomics, 73:521-526. DOI: 10.1016/j.jprot.2009.06.003.

Nie C, Ma L, Xia Y,Chao He, Jie Deng, Lingren Wang, Chong Cheng, ShudongS un,

Changsheng Zhao . 2015. Novel heparin-mimicking polymer brush grafted carbon nanotube/PES

composite membranes for safe and efficient blood purification. J Membr Sci, 475:455-468. DOI:

10.1016/j.memsci.2014.11.005. 
596 Davenport A, Drüeke T B, Nangaku M, Coates, P. T. 2015. High-volume plasma exchange in 597 patients with acute liver failure: an open randomized controlled trial. Kidney Int, 88:1215-1216. 598 DOI: 10.1016/j.jhep.2015.08.018. 
Figure 1

Overview of article selection process.
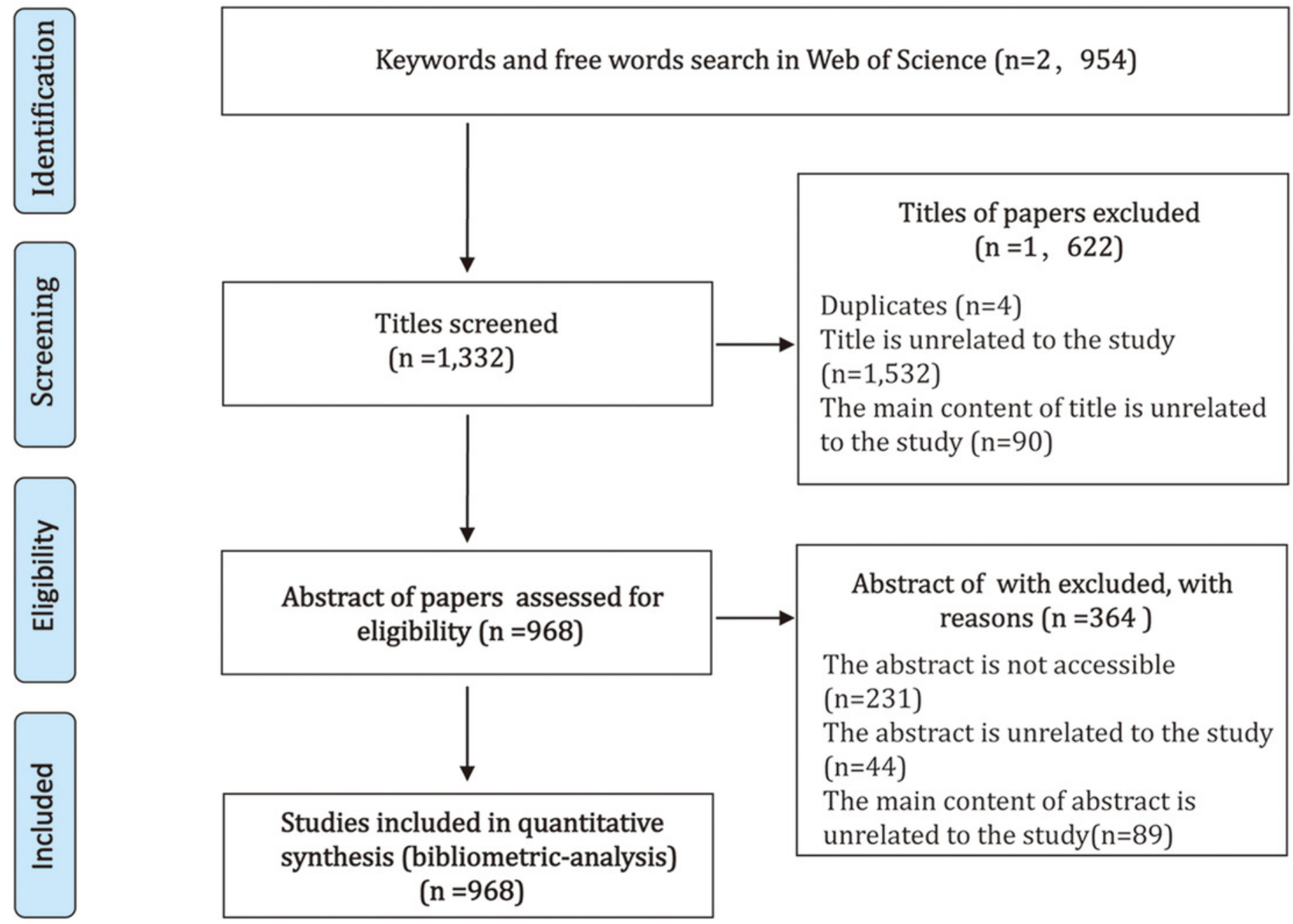

$$
\text { (n=968) }
$$


Figure 2

Numbers of included articles (A) and the growth trends of countries (B) from 2004 to 2017

Numbers of included articles (A) and the growth trends of countries (B) from 2004 to 2017 


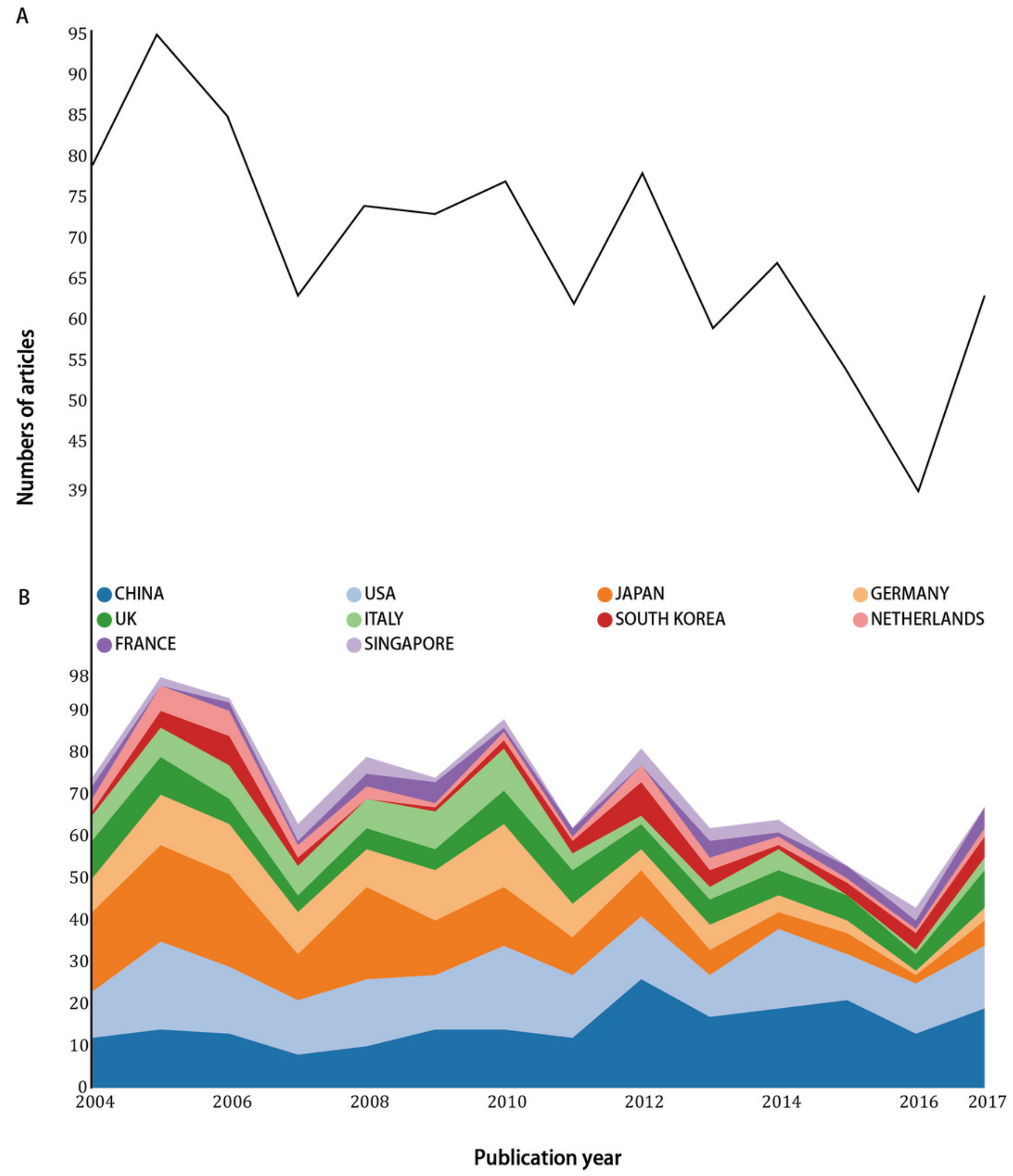


Figure 3

Interactions between countries of the included articles

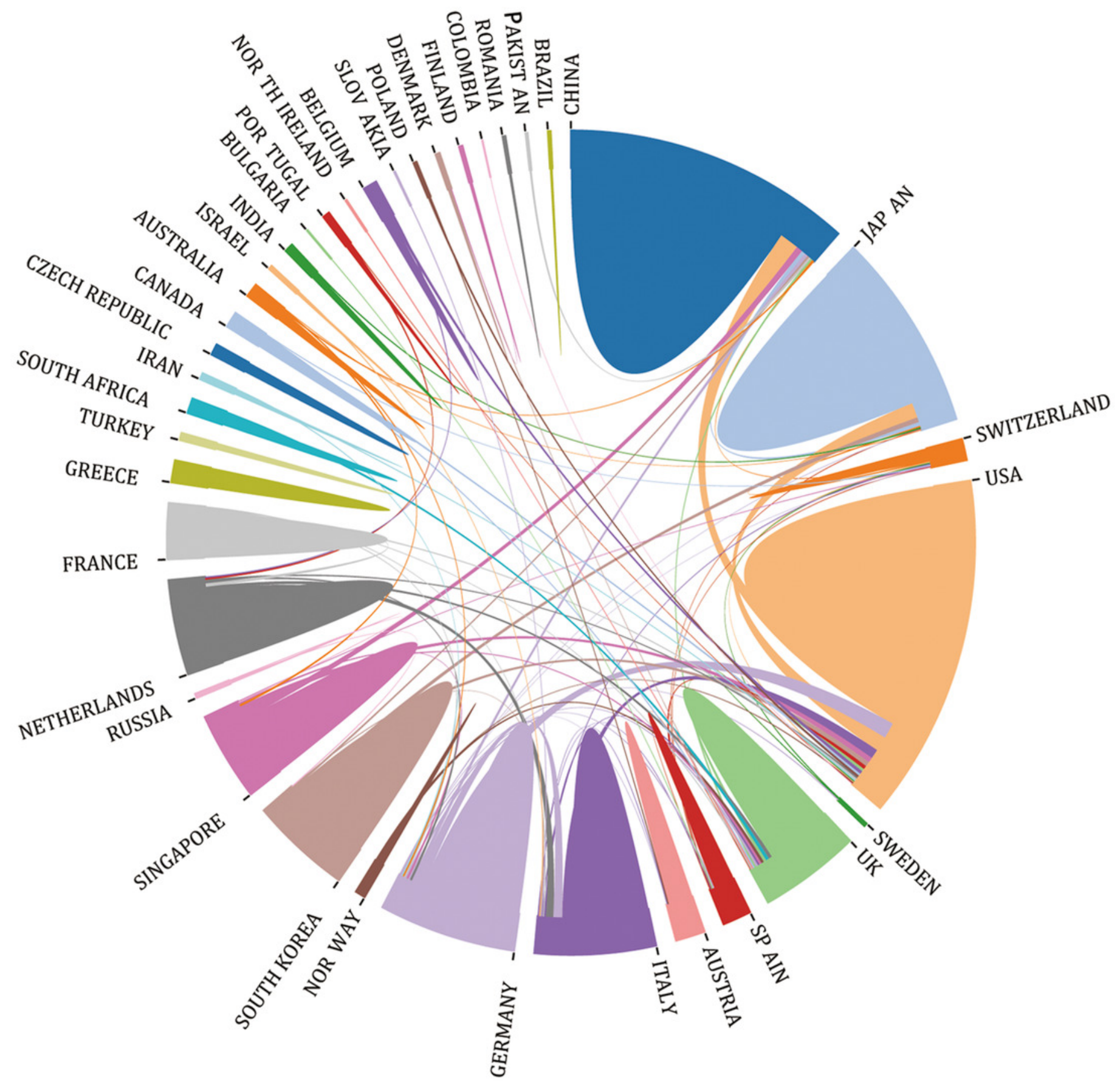


Figure 4

Correlations between the number of citations and the number of funding $(A)$, the number of years since publication (B), the number of countries $(C)$ and the number of authors (D).

A

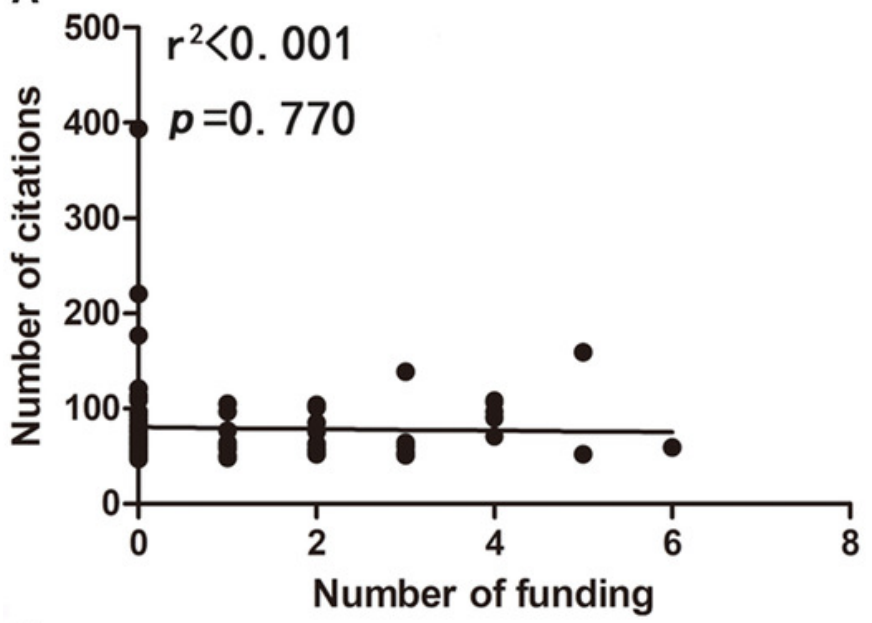

C

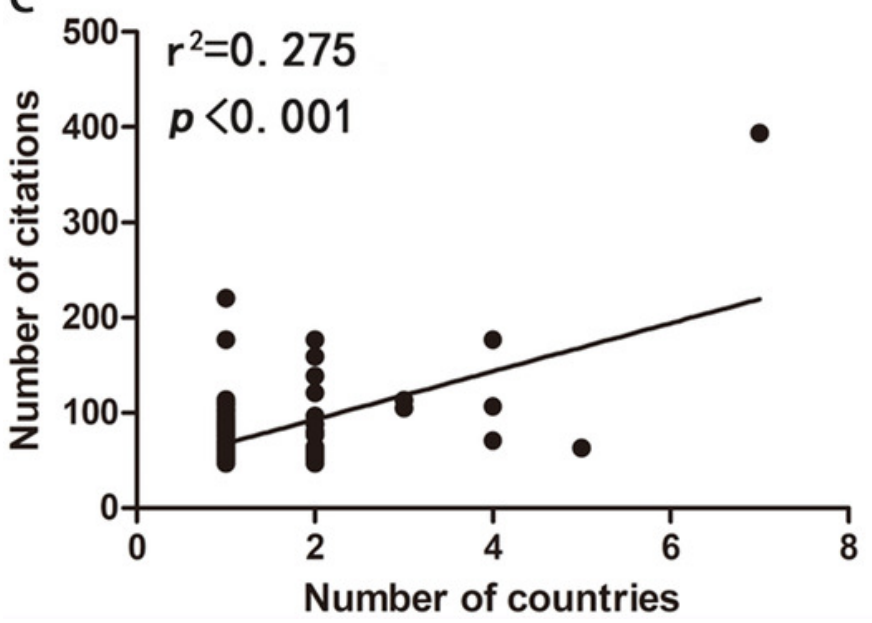

B

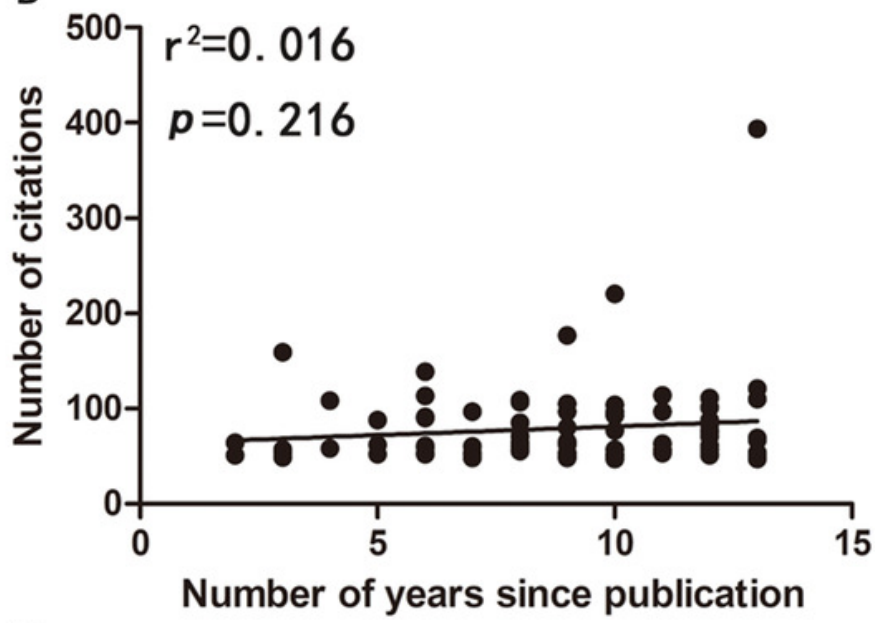

D

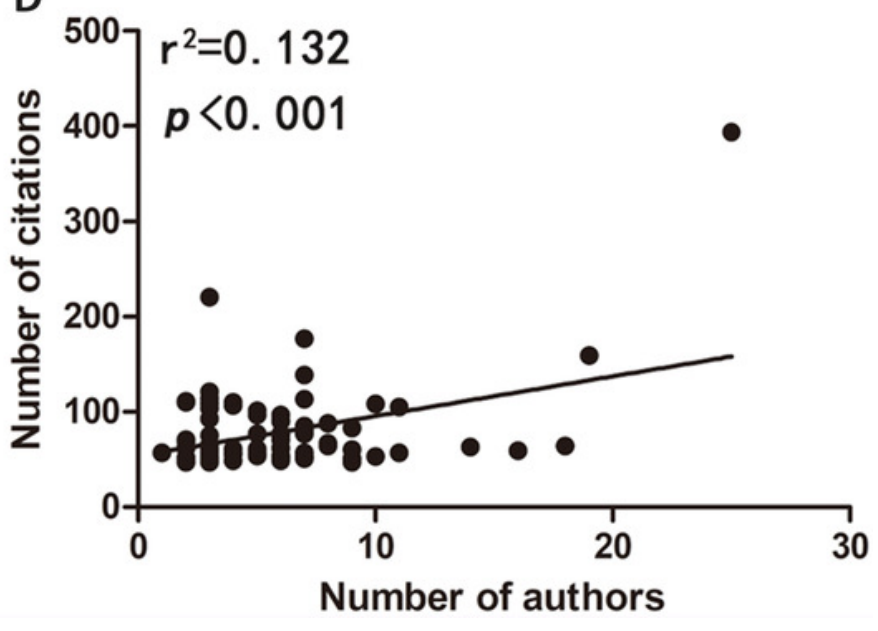


Figure 5

\section{Network map of authors (A), co-cited authors (B), institutions (C) and keywords (D)}

\section{Network map of authors (A), co-cited authors (B), institutions (C) and keywords (D)}
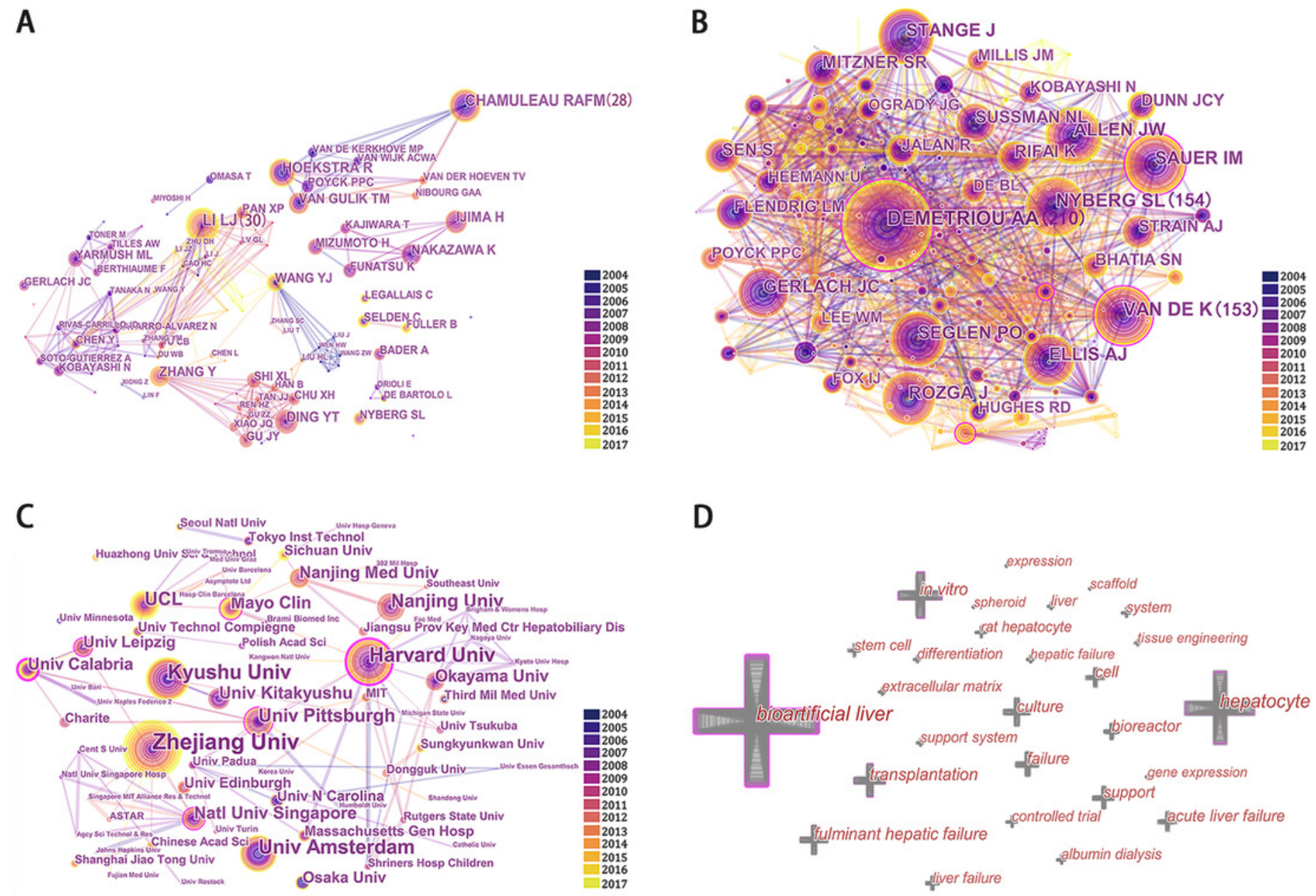


\section{Figure 6}

\section{Growth trends of keywords on artificial livers from 2004 to 2017 .}

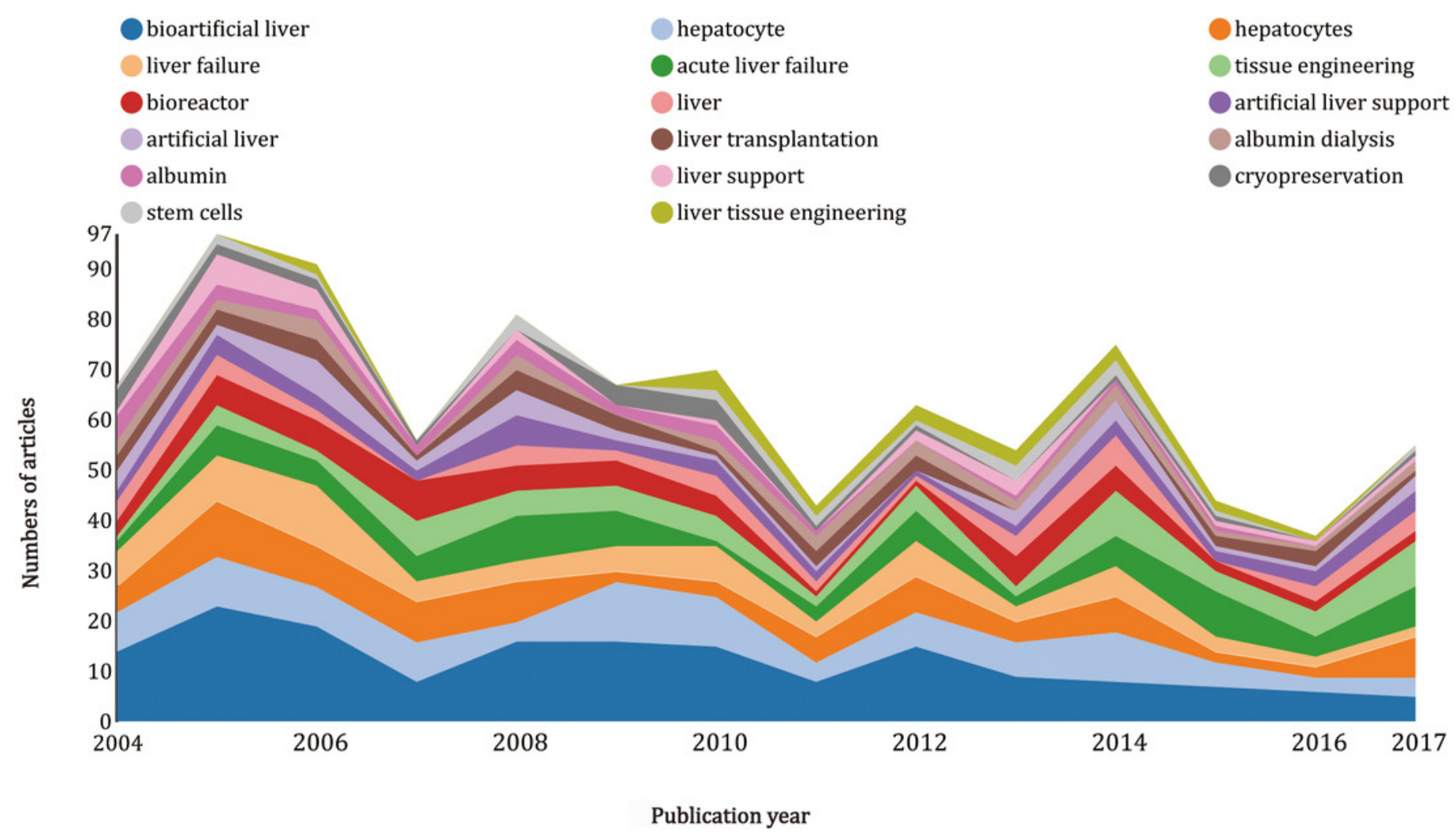




\section{Table 1 (on next page)}

T100 most-cited articles ranked by the number of Times cited 
Table 1 T100 most-cited articles ranked by the number of Times cited

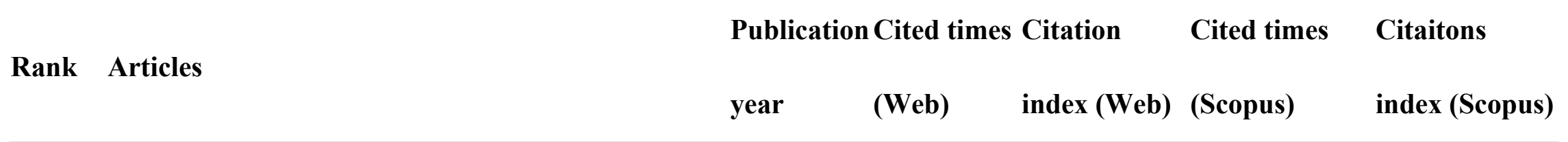

Demetriou A A, Jr B R, Busuttil R W, et al.

Prospective, randomized, multicenter, controlled

1 trial of a bioartificial liver in treating acute liver

2004

394

0.197

427

0.213

failure. [J]. Annals of Surgery, 2016, 239(5):667-

70.

Lee P J, Hung P J, Lee L P. An artificial liver

sinusoid with a microfluidic endothelial-like

2 barrier for primary hepatocyte culture[J]

$2007 \quad 220$

220

0.110

236

0.118

Biotechnology \& Bioengineering, 2007,

97(5):1340-6. 
engineering using gravity-enforced cell assembly[J]. Trends in Biotechnology, 2004, 22(4):195-202.

Medical applications of membranes: Drug

4 delivery, artificial organs and tissue engineering

Stamatialis D F, Papenburg B J, Gironés M, et al.

Medical applications of membranes: Drug

5 delivery, artificial organs and tissue

engineering[J]. Journal of Membrane Science, 2008, 308(1-2):1-34.

1 See additional files 1 for a complete list of T100 
Table 2 (on next page)

T18 Journals of the T100 publications were included 
Table 2 T18 Journals of the T100 publications were included

\begin{tabular}{|c|c|c|}
\hline Journal & $\begin{array}{l}\text { No. of articles } \\
\text { (citations) }\end{array}$ & $\begin{array}{l}\text { Impact factors } \\
(\mathbf{2 0 1 7 - 2 0 1 8 )}\end{array}$ \\
\hline BIOMATERIALS & $9(686)$ & 8.806 \\
\hline TISSUE ENGINEERING & $7(445)$ & 3.508 \\
\hline BIOTECHNOLOGY AND & $6(536)$ & 3.952 \\
\hline BIOENGINEERING & & \\
\hline LIVER TRANSPLANTATION & $6(502)$ & 3.752 \\
\hline JOURNAL OF HEPATOLOGY & $3(209)$ & 14.911 \\
\hline BIOMEDICAL MICRODEVICES & $3(159)$ & 2.077 \\
\hline BIOTECHNOLOGY LETTERS & $3(138)$ & 1.846 \\
\hline ANNALS OF SURGERY & $2(504)$ & 9.203 \\
\hline JOURNAL OF MEMBRANE & $2(228)$ & 6.578 \\
\hline
\end{tabular}




\begin{tabular}{|c|c|c|}
\hline \multicolumn{3}{|l|}{ SCIENCE } \\
\hline HEPATOLOGY & $2(198)$ & 14.079 \\
\hline TRENDS IN BIOTECHNOLOGY & $2(184)$ & 13.578 \\
\hline TRANSPLANT IMMUNOLOGY & $2(179)$ & 1.655 \\
\hline GUT & $2(160)$ & 17.016 \\
\hline \multicolumn{3}{|l|}{ JOURNAL OF CELLULAR AND } \\
\hline \multicolumn{3}{|l|}{ MOLECULAR MEDICINE } \\
\hline \multicolumn{3}{|l|}{ JOURNAL OF BIOACTIVE AND } \\
\hline \multicolumn{3}{|l|}{ COMPATIBLE POLYMERS } \\
\hline \multicolumn{3}{|l|}{ TISSUE ENGINEERING PART B- } \\
\hline \multicolumn{3}{|l|}{ REVIEWS } \\
\hline STEM CELLS & $2(115)$ & 5.587 \\
\hline \multicolumn{3}{|l|}{ WORLD JOURNAL OF } \\
\hline & $2(109)$ & 3.300 \\
\hline
\end{tabular}


1 N/A: not available. 


\section{Table 3 (on next page)}

The top five cited authors ranked by the number of articles 
Table 3 The top five cited authors ranked by the number of articles

\begin{tabular}{|c|c|c|c|c|c|c|c|}
\hline Rank & Authors & No. of articles & First & Citations of first & Correspond & Citations of correspond & Total citations \\
\hline 1 & Chamuleau, RAFM & 32 & 2 & 60 & 5 & 88 & 387 \\
\hline 2 & $\mathrm{Li}, \mathrm{LJ}$ & 31 & 3 & 26 & 28 & 122 & 127 \\
\hline 3 & Hoekstra, R & 29 & 3 & 17 & 16 & 121 & 346 \\
\hline 4 & Ding, YT & 24 & 0 & 0 & 19 & 97 & 113 \\
\hline 5 & Ijima, $\mathrm{H}$ & 24 & 7 & 25 & 13 & 43 & 76 \\
\hline
\end{tabular}

1 


\section{Table 4(on next page)}

The top five cited institutions of included articles on artificial livers 


\section{Table 4 The top five cited institutions of included articles on artificial livers}

\begin{tabular}{llll} 
Rank & Institution & No. of articles & No. of citations \\
\hline 1 & University of Amsterdam, AZ Amsterdam, Netherlands & 85 & 1066 \\
2 & Zhejiang University, Hangzhou City, Zhejiang Province, Peoples of Republic & 53 & 160 \\
3 & China & University of Pittsburgh, Pennsylvania, US & 49 \\
4 & National University of Singapore, Singapore & 44 & 211 \\
5 & Harvard University, Cambridge, Massachusetts, US & 40 & 211 \\
\hline
\end{tabular}




\section{Table 5(on next page)}

Keyword on artificial livers from 2004 to 2017 
Table 5 Keyword on artificial livers from 2004 to 2017

Domain Topic Percentage with Frequency of keyword occurrence(n)

keywords, \%

Bioartificial livers domain Human liver technology 15.74

(Total,57.40\%) academic medical center bioartificial liver (83), artificial liver (58), 3D cell culture (55), artificial liver support system (27), 3D models (26), Artificial (17), 3D co-culture (14), Hepatocyte cultivation (14), Liposome (12), engineered liver (11), artificial implantable devises (10), 3D (9), Genomics (8), Histology (8), 3D visualization (7), Cell culture (7), Human artificial mini chromosome (7), 
Bioartificial livers

10.19

device

Liver function index

Hepatocyte related

substance

Bioreactor
(8), Liver progenitor cell (8), Mesenchymal stem cell (8),

Bone marrow marrow mesenchymal stem cells (7), Feeder cells (7), Human hepatoblastoma cell line (7), High celldensity structures (7)

Flat-bed configuration (28), Fluidized bed (24), Scaffold (10), Biomaterials (11), Bioartificial liver assist device (11), Hybrid artificial liver (10), Bioartificial organs (9), Bioartificial (8), Bioartificial liver (8), Xenotransplantation (8), PERV (8)

A hepatic time (36), Autoimmune (25), Albumin synthesis (31), Growth factor (14), Glycosylation (10), Hepatic function (9), ALT (7)

Amanitaphalloides (95), Bilirubin (68), Alginate beads (62), Antioxidant (59), Endotoxin (29), Apheresis (20)

Airlift Reactor (78), Galactose (37), Flat membrane 
Blood purification Domain In vitro technique

(Total, 25.00\%) bioreactor (29), Bioreactor (12), Galactosylated membrane

(9),

Extracorporeal (30), Bioaffinity separation (18), Animal cell culture engineering (17), Hemodiafiltration (15), Fluid shear stress (14), Fractionated plasma separation and absorption (13), A combined rotational mold system (12), Molecular adsorb entre circulating system (12), Mass transfer (9), Extra corporeal liver perfusion (9), Hypothermia (8), Fluidization (7)

molecular substance

Ammonia (21), EROD (12), Medium (10), hemoglobinbased oxygen albumin (8), carrier (8), Acetaminophen (7), Midazolam (7), Glutathione S-transferase expression (7)

Extracellular substance 3.70

Extracellular matrix (24), EGF (20), E-Cadherin (18), Hepatic growth factors (13)

External device 2.77
Adsorption columns (17), Extracorporeal Liver Assist 
Clinical domain

(Total, $14.81 \%)$
Clinical treatment

8.33

6.48

Other artificial organs
2.78
Device (14), Energy systems (9)

Major hepatectomy (16), intra operative shunt (14),

Extended liver resection (13), Liver cell therapy (12),

Liver support treatment (12),

Gene therapy (10), Hepatocyte transplantation (8), Multi objective optimization (8), FDA guidelines (7)

Acute liver failure (15), Alcoholic hepatitis (13), end-stage

liver disease (11), acute-on-chronic liver failure (10),

Hepatic failure (9), Hepatocellular carcinoma (8), Acute poisoning (7),

Artificial heart blood pump (20), Artificial heart (clinical)

(13), Artificial bone (12) 
Table 6(on next page)

The top five cited research area 
1 Table 6 The top five cited research area

2

3

Ran

$1 \quad$ Biochemistry

$2 \quad$ Applied Microbiology

$3 \quad$ Cell Biology

21

4

Gastroenterology \& Hepatology

21

Engineering

16 